\title{
Time linkages between pollination onsets of different taxa in Perugia, Central Italy - an update
}

\author{
Giuseppe Frenguelli', Sofia Ghitarrini', Emma Tedeschini' \\ Department of Agricultural, Food and Environmental Sciences, University of Perugia, Italy \\ Frenguelli G, Ghitarrini S, Tedeschini E. Time linkages between pollination onsets of different taxa in Perugia, Central Italy - an update. Ann \\ Agric Environ Med. 2016; 23(1): 92-96. doi: 10.5604/12321966.1196860
}

\section{Abstract}

Introduction and objective. In the last decades, increasing attention has been paid to pollinosis. Numerous studies have been carried out concerning the pollination timing of allergenic plant species and the possibility to forecast its beginning and intensity using several statistical methods and models. This study proposes a simple and fast method to identify in advance the time lapse in which the pollination of some allergenic taxa should start.

Materials and methods. The times of pollination of 14 taxa were recorded in the area of Perugia (Central Italy) by means of a 7-volumetric Hirst-Type pollen trap. For a 30-year period (1984-2013), annual starting dates were calculated for each taxa, using the $5 \%$ method (Lejoly-Gabriel). The time linkages between these starting dates were then estimated, considering them in pairs and calculating linear regression coefficients.

Results. For the significantly linked species, forecasting models were obtained by means of linear regression analysis. To apply these models to the ongoing pollen season, pollination beginning of the earlier species has to be calculated using a sum-based method. From this date, through the obtained equations, it is possible to predict the approximate period in which the pollination of the second linked taxa should start.

Conclusions. The possibility to predict the start of the pollen season of these taxa could be of great importance from the allergological point of view. In fact, an early or delayed flowering can have considerable effects in the prophylaxis programming and efficacy.

\section{Key words}

pollen, pollination, linear models, forecasting

\section{INTRODUCTION}

In the last decades, a dramatic rise in patients suffering from pollinosis and airway disease has been observed [1, 2, 3, 4, 5]. Studies of aerobiology with emphasis on allergenic pollens have become increasingly numerous and extensive. In fact, the possibility to predict the beginning of the pollen season for the most allergenic taxa is crucial for planning pollen avoidance and adequate pharmacological therapies; Scadding et al. have shown how starting the medication two weeks before the pollen season markedly improves the efficacy [6]. Many studies have been carried out concerning the pollination timing of allergenic species and the possibility to forecast its beginning and intensity by using several statistical models $[7,8,9]$. These models are sometimes very complex, taking into account the environmental factors that influence flowering and thus pollination, such as meteorological conditions (especially temperatures) $[10,11,12]$ and daylight hours. Growing Degree Days (GDD) is probably the most common pheno-climatic model used to forecast the flowering time $[13,14,15,16,17]$. In Perugia (Umbria-Central Italy) the aerobiological monitoring has been active continuously since 1982, and the great quantity of data collected can be processed to obtain a lot of information about pollen seasons of many allergenic taxa. In fact, some models of pollen season

Address for correspondence: Sofia Ghitarrini, University of Perugia, Department of Agricultural, Food and Environmental Sciences Borgo XX Giugno 74, 06121 Perugia, Italy

E-mail: sofia.ghitarrini@unipg.it

Received: 25 February 2015; accepted: 15 September 2015 forecast have already been published $[18,19,20]$, and other works are in progress [21]. In 1995, Bricchi et al. proposed a simple model of time linkage between the pollination onsets of 14 taxa monitored in the area of Perugia from 1982-1992 [22]. This model relies on the fact that the phenological development of some species can be used as an 'indicator' to predict phenophases occurrence in other species. They showed how, starting from the correlation existing in the flowering dates of some taxa, these can be forecasted using a statistical model based on linear regression, which does not require meteo-climatic information.

\section{OBJECTIVE}

This study aims at updating the model proposed in 1995 by Bricchi et al. [22]. Data on pollination of 12 taxa, collected in a 30-year period (1984-2013) were integrated and analysed to calculate more precisely the time linkages between their pollination onsets, and thus to forecast their approximate beginning date through an updated form of the regressionbased model.

\section{MATERIALS AND METHOD}

Pollen grains were collected using a 7-day volumetric HirstType [23] pollen trap (Lanzoni, Bologna) located in Perugia on the rooftop of the Department of Agricultural, Food and Environmental Science, at about $20 \mathrm{~m}$ above ground level. 
Perugia lies on a hill (493 m above sea level) and overlooks the middle valley of the river Tevere, between Lake Trasimeno and the Tyrrenian side of the Marches-Umbrian Appenine Mountains. The climate can by classified as sub-continental by means of continentality index [24]. For each taxon, over a 30-year period (1984-2013) of pollen monitoring, dates of the beginning of the main pollen season (MPS) were calculated using the Lejoly-Gabriel method (starting on the day by which $5 \%$ of annual total pollens had been released) [25]. The time linkages between these starting dates were then estimated considering them in pairs and calculating the linear regression coefficients. Forecasting models were obtained by means of linear regression analysis.

\section{RESULTS}

Mean date of pollination start, its standard deviation, earliest date, latest date and the ranges between these were calculated for the 12 analysed taxa (Tab. 1). Some taxa showed high year-to- year variability in the date of their pollination onset. For example, Corylus and Ulmus have ranges of 55 and 42 days, respectively. This behaviour is particularly recognisable in taxa flowering in winter and spring, especially arboreous ones, the main cause being that winter duration and temperatures control the pollination onset of various tree species. Following an unusually short, warm winter, many trees bloom early in the season, but an unusually long winter will delay the date of pollination [22]. Also, Pinus, with its 49-days long range, seems to undergo this effect, despite having a slightly later flowering period.

Table 1. Beginning of the main pollen season (MPS)

\begin{tabular}{llrllc}
\hline & Mean date & S.D. & Earliest date & Latest date & Range (days) \\
\hline Corylus & 15 Jan (15) & 12 & 29 Dec (-3) & 21 Feb (52) & 55 \\
\hline Ulmus & 18 Feb (49) & 10 & 3 Feb (34) & 17 Mar (76) & 42 \\
\hline Populus & 3 Mar (62) & 8 & 14 Feb (45) & 20 Mar (79) & 34 \\
\hline Salix & 22 Mar (81) & 9 & 7 Mar (66) & 8 Apr (98) & 32 \\
\hline Platanus & 2 Apr (92) & 9 & 19 Mar (78) & 21 Apr (112) & 34 \\
\hline Pinus & 15 Apr (105) & 12 & 23 Mar (82) & 11 May (131) & 49 \\
\hline Quercus & 27 Apr (117) & 6 & 12 Apr (102) & 8 May (128) & 26 \\
\hline Gramineae & 2 May (122) & 7 & 15 Apr (105) & 17 May (138) & 33 \\
\hline Plantago & 11 May (131) & 17 & 14 Apr (104) & 22 Jun (173) & 69 \\
\hline Olea & 2 Jun (153) & 7 & 20 May (140) & 22 Jun (173) & 33 \\
\hline Castanea & 17 Jun (168) & 7 & 2 Jun (153) & 28 Jun (180) & 27 \\
\hline Artemisia & 7 Aug (219) & 4 & 28 Jul (210) & 17 Aug (229) & 19 \\
\hline
\end{tabular}

(S.D. - Standard Deviation; numbers in brackets indicate conversion of the dates in number of days from 1 January)

On the other hand, some taxa showed ranges shorter than 30 days (Quercus - 26 days, Castanea - 27 days, Artemisia - 19 days) which are more typical for late spring/summer flowering species that are not influenced by the duration of winter. In addition, it has to be considered that while the flowering of early spring plants is greatly influenced by temperatures, late spring and summer flowering species also undergo the effect of photoperiod, which does not vary from year to year.

An exception in this study is represented by Plantago: its mean pollination onset date is 11 May, but it shows the

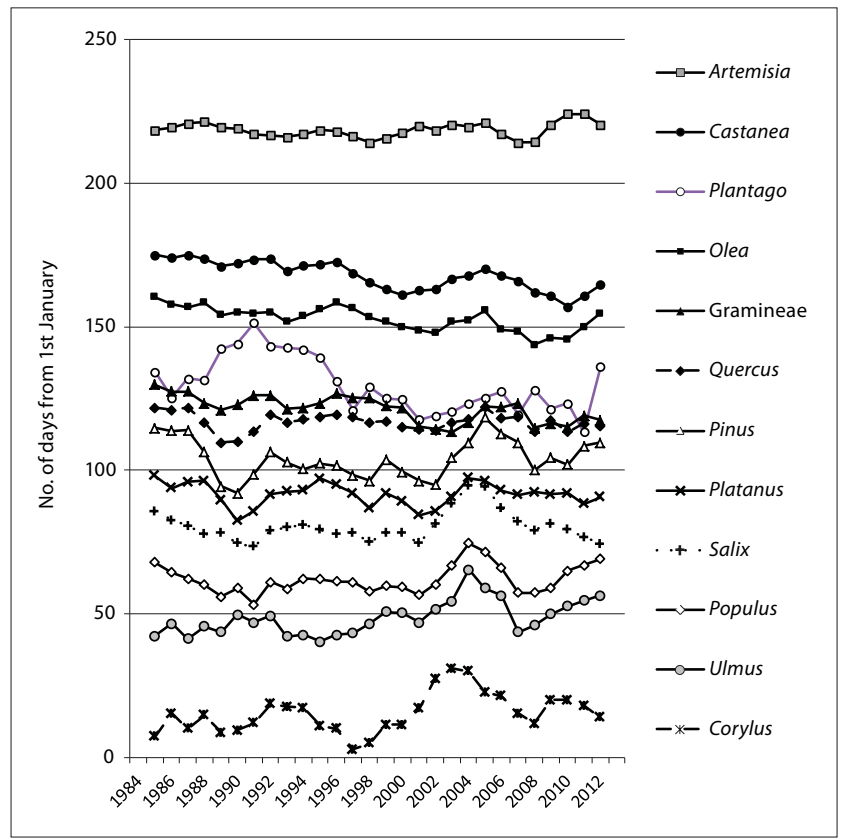

Figure 1. Dates of start of pollination (centred moving averages of three consecutive years) for the 12 taxa over the studied period

maximum registered range (69 days), having pollination onset dates between 14 April (2008) - 22 June (2013) in the 30 considered years.

Figure 1 shows the trends of the pollination onset for the 12 studied taxa. As observed by Bricchi et al. in 1995 [22], Corylus and Artemisia show particular pollination patterns. The beginning of their pollen season does not seem to be linked to any of the other taxa (Tab. 2). The only isolated exception is a linear regression coefficient of 0.608 between the pollination onsets of Corylus and Ulmus, which is quite close to their natural pollination starting periods. The reason for this almost total 'unlinkage' could be that Corylus avellana is the first species flowering in January and, as already stated it is strongly influenced by temperature requirements to be released from dormancy, resume growth, and bloom [26]. Thus, its beginning, relying on the temperatures in the immediately preceding period, is untied from the later ones (except Ulmus). Instead, the pollination start of Artemisia could be unrelated with all the others because of its good constancy in time (lowest standard deviation and range).

The yearly onset dates of each taxon were correlated in pairs to investigate if there were linkages between the beginning of flowering of the studied species. Time linkages between the start of the main pollen season of different plants could be of great importance for constructing forecasting models capable of predicting the flowering period of a species, starting from the pollination of previous ones. All the $r$ coefficients, obtained with the linear regression method, are shown in Table 2, together with their level of significance. Highest significant correlations were obtained for taxa whose flowering periods are close, but there were some cases of strong correlation also between taxa with a range between their mean pollination onset dates (warning days, WD) higher than 30 days (Gramineae/Castanea, 47 WD; Quercus/ Olea, 36 WD; Corylus/Ulmus, 34 WD; Gramineae/Olea, 32 WD).

Table 3 shows the couples of taxa with the highest correlation levels, their linear regression coefficients 
Table 2. Linear regression coefficients

\begin{tabular}{|c|c|c|c|c|c|c|c|c|c|c|c|c|}
\hline & Artemisia & Castanea & Olea & Plantago & Gramineae & Pinus & Quercus & Platanus & Salix & Populus & Ulmus & Corylus \\
\hline Corylus & 0.259 & 0.125 & 0.174 & 0.099 & 0.321 & 0.303 & 0.125 & 0.111 & 0.334 & 0.150 & $0.608^{* * *}$ & - \\
\hline Ulmus & 0.252 & 0.167 & 0.090 & 0.017 & 0.330 & 0.227 & 0.019 & 0.048 & 0.331 & $0.506^{* *}$ & - & \\
\hline Populus & 0.358 & 0.051 & 0.281 & 0.130 & 0.070 & $0.496^{* *}$ & 0.349 & $0.456^{* *}$ & $0.647^{* * *}$ & - & & \\
\hline Salix & 0.163 & 0.059 & 0.180 & 0.193 & 0.129 & $0.518^{* *}$ & $0.380^{*}$ & $0.565^{* *}$ & - & & & \\
\hline Platanus & 0.071 & 0.281 & $0.477^{* *}$ & 0.039 & 0.346 & $0.641 * * *$ & $0.494^{* *}$ & - & & & & \\
\hline Pinus & 0.304 & $0.379^{*}$ & $0.497^{* *}$ & 0.033 & $0.412^{*}$ & - & & & & & & \\
\hline Gramineae & 0.097 & $0.592^{* * *}$ & $0.671^{* * *}$ & 0.020 & - & & & & & & & \\
\hline Plantago & 0.094 & $0.396^{*}$ & 0.229 & - & & & & & & & & \\
\hline Olea & 0.211 & $0.770^{* * *}$ & - & & & & & & & & & \\
\hline Castanea & 0.006 & - & & & & & & & & & & \\
\hline
\end{tabular}

${ }^{*} \mathrm{p}<0.05 ;{ }^{* *} \mathrm{p}<0.01 ;{ }^{* * *} \mathrm{p}<0.001$

Table 3. Correlation coefficients ( $r$ ) of starting dates of the main pollen season between different taxa over a 30-year period and forecasting model. For the taxa which, combined in pairs, gave the highest coefficients of linear regression (coefficients $>0.547$ ), mean warning days before the start of pollination of the second taxon of the pair and forecasting models are shown. Coefficients of determination $\left(R^{2}\right)$ is higher than 0.5 only for the first two models, which fit the best

\begin{tabular}{lccc}
\hline $\begin{array}{l}\text { Correlated } \\
\text { taxa }\end{array}$ & $\begin{array}{c}r \text { coefficient } \\
\left.\text { (and } \mathrm{R}^{2}\right)\end{array}$ & $\begin{array}{c}\text { Mean } \\
\text { warning } \\
\text { days }\end{array}$ & $\begin{array}{c}\text { Forecasting model and standard } \\
\text { error }\end{array}$ \\
\hline $\begin{array}{l}\text { Pinus } \rightarrow \\
\text { Quercus }\end{array}$ & $0.816^{* * *}(0.666)$ & 12 & $\mathrm{y}_{\text {quercus }}=0.3998 \mathrm{x}_{\text {pinus }}+75.074 \pm 6.865$ \\
\hline $\begin{array}{l}\text { Olea } \rightarrow \\
\text { Castanea }\end{array}$ & $0.770^{* * *}(0.592)$ & 15 & $\mathrm{y}_{\text {castanea }}=\begin{array}{c}0.719 \mathrm{x}_{\text {olea }}+57.926 \\
\pm 4.239\end{array}$ \\
\hline $\begin{array}{l}\text { Gramineae } \rightarrow \\
\text { Olea }\end{array}$ & $0.671^{* * *}(0.450)$ & 32 & $\mathrm{y}_{\text {olea }}=0.6706 \mathrm{x}_{\text {gramineae }}+71.878 \pm$ \\
\hline $\begin{array}{l}\text { Populus } \rightarrow \\
\text { Salix }\end{array}$ & $0.647^{* * *}(0.419)$ & 18 & $\mathrm{y}_{\text {salix }}=\begin{array}{c}0.7067 \mathrm{x}_{\text {populus }}+36.357 \\
\pm 6.992\end{array}$ \\
\hline $\begin{array}{l}\text { Platanus } \rightarrow \\
\text { Pinus }\end{array}$ & $0.641^{* * *}(0.411)$ & 13 & $\mathrm{y}_{\text {pinus }}=0.8653 \mathrm{x}_{\text {platanus }}+25.228$ \\
\pm 9.116
\end{tabular}

${ }^{*} p<0.05 ;{ }^{* *} p<0.01 ;{ }^{* * *} p<0.001$

$(r)$, coefficients of determination $\left(\mathrm{R}^{2}\right)$, warning days and forecasting models. Obviously, the more anticipated the forecast is, the more useful it is. As mentioned above, the longest-term forecast models are those obtained starting from Gramineae for Castanea $(\mathrm{p}<0.001)$ and Olea $(\mathrm{p}<0.001)$, from Corylus for Ulmus ( $\mathrm{p}<0.001)$ and from Quercus for Olea $(\mathrm{p}<0.01)$. Medium-term forecast $(10-20 \mathrm{WD})$ are possible by applying the model to Populus for Salix (11 WD; $<<0.001$ ); Salix for Platanus (11 WD; $\mathrm{p}<0.01)$; Pinus for Quercus (12 WD; $\mathrm{p}<0.001$ ); Platanus for Pinus (13 WD; $<<0.001$ ); Olea for Castanea (15 WD; $<0.001)$. Finally, a short-term linkage was found between Quercus and Gramineae (5 WD; $<<0.01)$.

\section{DISCUSSION}

As mentioned previously, a species whose pollination is linked to that of another gives information in forecasting the pollination of the latter, providing warning days. Every year, a specific equation should be used to forecast the onset of pollination of a particular taxon. The general model is $y_{\text {date }}=\mathrm{a} x_{\text {date }}+\mathrm{b}$ ( \pm standard error); once the pollination of the former species begins $\left(x_{\text {date }}\right)$, the $y_{\text {date }}$ value can be calculated by means of the forecast equation models shown in Table 3 , in order to obtain the probable date of the start of pollination of the latter species, and a 'risk interval' of time around it (result: $\mathrm{y}_{\text {date }}=$ start date expressed in number of days from 1 January \pm error days). Despite the significant $r$ coefficients displayed, $\mathrm{R}^{2}$ coefficients are not very high (except those for Pinus Quercus and Olea - Castanea regressions), showing that the model's accuracy on the observed data is quite low. This was predictable, because using a simple linear regression to describe a process influenced by a multitude of factors, such as the beginning of pollination, implies an over-simplification. More effective models are obtained when meteo-climatic conditions are considered [8]. The presented study, anyway, proposes a simple and fast method to identify in advance the time lapse in which the pollination of the taxa should begin, and the linear regression has proven to work for this purpose. The graphic in Figure 2 shows a comparison between the start dates for the pollination of Olea detected by monitoring ( $\mathrm{x}$-axis) and calculated using the equation obtained by means of Gramineae linkage (y-axis). The distribution of values around the regression line, $r$ coefficient and $p$ value prove that the model is fairly reliable.

The application of this model requires a particular approach to calculate the starting date of a taxon when we want to forecast the beginning of flowering of another one linked to it before the former has finished its pollen season. In fact, the $5 \%$ method cannot be used until the season ends and the pollen index (yearly total pollen count) can be calculated for the current year. Therefore, an alternative system based on the cumulative thresholds $[27,28]$ is proposed. As there is no consensus on what threshold should be used to define the start of a pollen season, they were obtained with the following elaboration: for each one of the 12 analysed taxa, the mean pollen index has to be extrapolated from data of the 30 years of the study. The $5 \%$ fraction of this mean pollen index is 


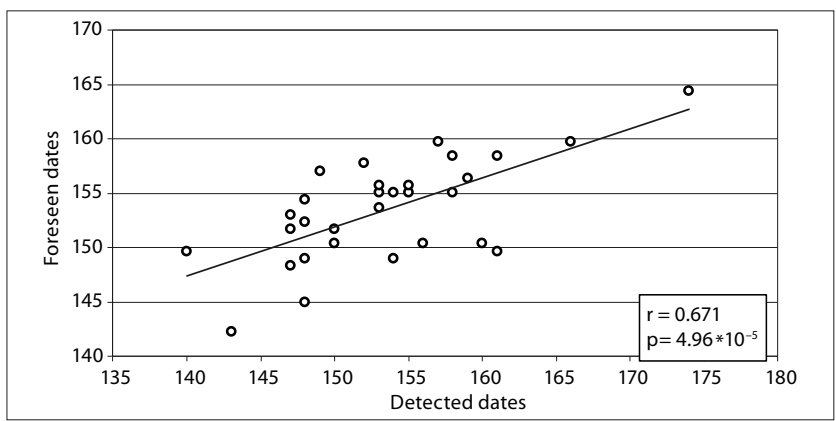

Figure 2. Start dates for the pollination of Olea in the 1984-2013 period. Correlation between detected dates and foreseen ones, calculated using the equation obtained by means of Gramineae linkage (values indicate the number of days from 1st January). $p$ value proves that the model is reliable
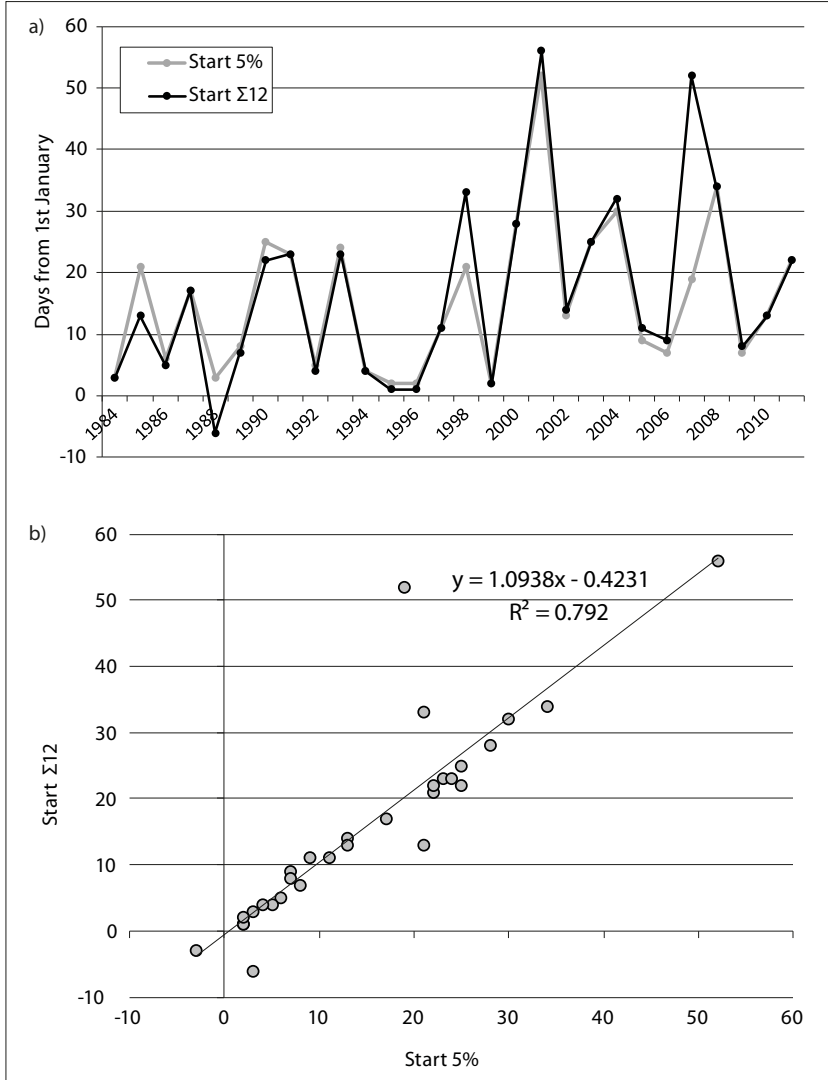

Figure 3. a) The graphic plots the starting dates of the main pollen season of Corylus from 1984 to 2013. Gray line refers to the onset dates calculated with the $5 \%$ method, while black one to those calculated with the sum method. We used as threshold the number of 12 pollen grains, extrapolated as $5 \%$ of the mean pollen index (see table 3). b) Regression line of the distibution of the two series of onset dates. The slope of the line is very close to 1 , indicating a substantial equivalence between the data sets (linear regression coefficient $=0,89, R 2=0,792, p<0,001$ ).

calculated, and used as threshold of the sum method to establish extemporarily the onset of that taxa for the ongoing season. This strategy allows having the $x_{\text {date }}$ immediately disposable to forecast the starting date of the following linked species $\left(y_{\text {date }}\right)$, applying the models in Table 3 . Table 4 shows all the mean pollen indexes and thresholds obtained. As an example, Figure 3 shows two graphics comparing the starting dates of Corylus pollen season from 1984 - 2013, calculated with the $5 \%$ method and the $\Sigma 12$ method. It is clear that the two models overlap almost perfectly (Fig. 3a), and are statistically equivalent (Fig. 3b). These observations legitimate the use of the sum method for the ongoing year,
Table 4. Mean yearly total pollen counts (pollen index, P.I.) observed for each taxa in the area of Perugia and their $5 \%$ fractions, to be used as threshold to establish the start date of the current pollen season with the sum method

\begin{tabular}{lcc}
\hline & Mean Pollen Index (1984-2013) & 5\% of mean P.I. ( threshold) \\
\hline Corylus & 250 & 12 \\
\hline Ulmus & 266 & 13 \\
\hline Populus & 389 & 19 \\
\hline Salix & 131 & 7 \\
\hline Platanus & 172 & 9 \\
\hline Pinus & 415 & 68 \\
\hline Quercus & 16 & 800 \\
\hline Gramineae & 3.73 & 187 \\
\hline Plantago & 191 & 10 \\
\hline Olea & 3.42 & 171 \\
\hline Castanea & 592 & 30 \\
\hline Artemisia & 154 & 8 \\
\hline
\end{tabular}

while the forecasting models are constructed using start dates calculated with the $5 \%$ method. It has to be considered that these thresholds, being alculated on the data set collected in Perugia (Central Italy), reflect the characteristics that the pollen seasons of those taxa have in this specific area. In different zones, both the models and the thresholds should be adapted using the area-specific data set.

\section{CONCLUSIONS}

The existence of a data set constructed over more than 30 years of aerobiological monitoring in Perugia (Central Italy), has allowed reliable estimation of the linkage between the pollination onset dates of several species. The possibility to predict the start of the pollen season of the taxa presented in this study could be of great importance from the allergological point of view. In fact, an early or delayed flowering can have considerable effects on the prophylaxis programming and efficacy.

The forecasting model here proposed is simple and purely statistic: it does not involve meteorological parameters, using instead the significant correlation existing between the occurrence of the flowering phenophase in various species. A multiple regression approach, involving other variables, e.g. data about temperatures and rainfall, would surely produce a better fitting and precise model, but would not be as fast and easy to apply. Moreover, these models are very useful in all those cases in which forecasting must be carried out in climatically heterogeneous areas, such as the Perugia region.

\section{REFERENCES}

1. Corsico R, Falagiani P, Ariano R, Berra D, Biale C, Bonifazi F, et al. An epidemiological survey on the allergological importance of some emerging pollens in Italy. J Investig Allergol Clin Immunol. 2000; 10(3): 155-161.

2. Asero R. Analysis of new respiratory allergies in patients monosensitized to airborne allergens in the area north of Milan. J Investig Allergol Clin Immunol. 2004; 14(3): 208-213.

3. Eder W, Ege MJ, von Mutius E. The ashtma epidemic. N Engl J Med. 2006; 355: 2226-2235. 
4. D’Amato G, Cecchi L, Bonini S, Nunes C, Annesi-Maesano I, Behrendt $\mathrm{H}$, et al. Allergic pollen and pollen allergy in Europe. Allergy. 2007; 62: 976-990.

5. Hofmaier S. Allergic airway diseases in childhood: an update. Pediatr Allergy Immunol. 2014 (Epub ahead of print); DOI: 10.1111/pai.12322.

6. Scadding GK, Durham SR, Mirkian R, Jones NS, Leech SC, Farooque S, et al. BSACI guidelines for the management of allergic and non-allergic rhinitis. Clin Exp Allergy. 2008; 38(1): 19-42.

7. Rodríguez-Rajo FJ, Valencia-Barrera RM, Vega-Maray AM, Suárez FJ, Fernández-González D, Jato V. Prediction of airborne Alnus pollen concentration by using ARIMA models. Ann Agric Environ Med. 2006; 13(1): 25-32.

8. Kasprzyk I. Forecasting the start of Quercus pollen season using several methods - the evaluation of their efficiency. Int J Biometeorol. 2009; 53: 345-353.

9. Siniscalco C, Caramiello R, Migliavacca M, Busetto L, Mercalli L, Colombo R, et al. Models to predict the start of the airborne pollen season. Int J Biometeorol. 2014 (Epub ahead of print); DOI: 10.1007/ s00484-014-0901-x.

10. Oteros J, García-Mozo H, Hervás C, Galán C. Biometeorological and auto regressive indices for predicting olive pollen intensity. Int $\mathrm{J}$ Biometeorol. 2013; 57(2): 307-316

11. Myszkowska D. Predicting tree pollen season start dates using thermal conditions. Aerobiologia. 2014; 30(3): 307-321.

12. Pauling A, Regula G, Bernard C. Toward optimized temperature sum parameterizations for forecasting the start of the pollen season. Aerobiologia. 2014; 30(1): 45-57.

13. Frenguelli G, Bricchi E. The use of pheno-climatic model for forecasting the pollination of some arboreal taxa. Aerobiologia. 1998; 14:39-44.

14. García Mozo H, Galán C, Gomez Casero MT, Dominguez Vilches E. A comparative study of different temperature accumulation methods for predicting the start of Quercus pollen season in Córdoba (South West Spain) Grana. 2000; 39: 194-199.

15. Galán C, García Mozo H, Vásquez L, Ruiz L, Díaz de la Guardia C, Trigo MM. Heat requirement for the onset of the Olea europaea L. pollen season in several sites in Andalusia and the effect of the expected future climate change. Int J Biometeorol. 2005; 49: 184-188.

16. Fuertes- Rodríguez CR, Ganzález-Parrado Z, Vega-Maray AM, Valencia-Barrera RM, Fernández-González D. Effect of air temperature on forecasting the start of Cupressaceae pollen type in Ponferrada (León, Spain). Ann Agric Environ Med. 2007; 14(2):237-42.

17. Zhang Y, Bielory L, Cai T, Mi Z, Georgopoulos P. Predicting onset and duration of airborne allergenic pollen in the United States. Atmos Environ. 2015; 103:297-306.

18. Frenguelli G, Bricchi E, Romano B, Mincigrucci G, Spieksma FThM. A predictive study on the pollen season for Graminaceae and Olea europaea L. Aerobiologia. 1989; 5(1): 62-70.

19. Frenguelli G, Bricchi E, Romano B, Mincigrucci F, Fornaciari M, Goretti G. Pollen forecast for some taxa in central Italy. Proceedings of the International Symposium on pollinosis in the Mediterranean Area; Mar 16-18 1989; Naples, Italy. p. 148.

20. Frenguelli G, Spieksma FThM, Bricchi E, Romano B, Mincigrucci F, Nikkels AH et al. The influence of air temperature on the starting dates of the pollen season of Alnus and Populus. Grana. 1991; 30:196-200.

21. Frenguelli G, Ghitarrini S, Tedeschini E. Possible relation between climate change and pollination of grasses in central Italy. Proceedings of the $10^{\text {th }}$ International Congress of Aerobiology; Sep 22-26 2014; Sydney, Australia.

22. Bricchi E, Frenguelli G, Mincigrucci G, Fornaciari M, Ferranti F, Romano B. Time linkages between pollination onsets of different taxa over an 11-year period in Perugia, Central Italy. Aerobiologia. 1995; 11: 57-61.

23. Hirst JM. An automatic volumetric spore trap. Ann Appl Biol. 1952; 39:257-265.

24. Conrad V, Pollak LW. Method in climatology. $2^{\text {nd }}$ Edition. Harvard university press, Cabridge, Massachussetts. 1950.

25. Lejoly-Gabriel M. Recherches écologiquessur la pluie pollinique en Belgique. Acta Geogr. Lovaniensia, Vol.13. Institut de géographie, Université catholique de Louvain, 1978.

26. Frenguelli G, Bricchi E, Romano B, Mincigrucci G, Ferranti F, Antognozzi $\mathrm{E}$. The role of air temperature in determining dormancy release and flowering in Corylus avellana L. Aerobiologia. 1992; 8: $415-418$.

27. Driessen MNBM, van Herpen RMA, Moelands RPM, Spieksma FThM. Prediction of the start of the grass pollen season for the western part of Netherlands. Grana. 1989; 28:37-44.

28. Driessen MNBM, van Herpen RMA, Smithuis LOMJ. Prediction of the start of the grass pollen season for the southern part of the Netherlands. Grana. 1990; 29: 79-86. 